\title{
PLANT PEST INFORMATION NETWORK (PPIN): AN ACTIVE INFORMATION SYSTEM TO SUPPORT PLANT PROTECTION RESEARCH
}

\author{
K.L. BEAL \\ MAF Quality Management, New Zealand Plant Protection Centre (Lincoln) \\ PO Box 24, Gerald Street, Lincoln, Mid Canterbury
}

Surveillance information is the cornerstone of both agricultural security and market access for New Zealand. The knowledge of our pest and disease status is used to develop quarantine specifications and to support negotiations with our trading partners. A key component of New Zealand's surveillance programme is reporting new plant pest records as facilitated by the Biosecurity Act 1993. The type of new plant pest records required to be reported include: organisms that are new to New Zealand, new plant pest host associations, new plant pest distributions. The Plant Pest Information Network (PPIN, pronounced 'pippin') is a national database and scientific network for the collection, collation, management and dissemination of plant pest surveillance information. PPIN is maintained by MAF Quality Management (MQM) on behalf of MAF Regulatory Authority (MAF RA). It holds records of pest/organism occurrence, their hosts and distribution, including fungi, bacteria, viruses, nematodes, insects etc. Currently PPIN holds approximately 6,000 association records and 7,000 observation records for main import/export crops. Other crops will be included as information becomes available. Support and input from the scientific community is necessary to help build and maintain an accurate, up to date set of surveillance data for New Zealand. New or un/published records should be forwarded to the PPIN Administrator for their inclusion in the PPIN database. Allied organisations and the public are able to make use of the collated data which will be probably be made available via Internet.

\section{PROFILE FROM THE PAST: 50 YEARS OF THE NEW ZEALAND PLANT PROTECTION SOCIETY}

\section{J.F. PEARSON}

\section{Grasslands, AgResearch, PO Box 60, Lincoln}

In August 1948, an energetic group of Cantabrians organised the Society's first successful two day National Weeds Conference at Lincoln College. The purpose of the Society was to encourage dissemination of the latest information, with a view to increasing farm production. Papers were presented by scientific and commercial personnel and prominent farmers. In the mid 1950's the yearly conference venues widened from the two Agricultural Colleges and subsequently were hosted at 19 locations throughout New Zealand. The programme length was increased with the introduction of a field day. Early emphasis was placed on publication of the conference Proceedings, initially printed post conference. A change to A5 format occurred in 1952 and since 1973 each volume was pre-printed and circulated prior to the conference. The 50 conference Proceedings have chronicled advances in New Zealand's agriculture and horticulture. In 1956, a photograph recorded the 88 participants of the Timaru Conference. Membership of the Society has grown to $>300$, while the Society underwent four name changes and two logo designs. Life membership was created in 1968 to recognise noteworthy contribution by members. 